\title{
Leak-Before-Break methodology applied to different piping materials: a performance evaluation
}

\author{
Israel Gleybson Ferreira da Silva \\ Navy Technological Center in São Paulo, Brazil \\ rael_gfs@hotmail.com
}

\author{
Arnaldo Homobono Paes de Andrade, Waldemar Alfredo Monteiro \\ Nuclear and Energy Research Institute, Brazil \\ arnaldo.homobono@gmail.com \\ wamontei@ipen.br
}

\begin{abstract}
This paper presents a study of the application of Leak-BeforeBreak (LBB) to nuclear piping using three different materials. Although had been introduced more than three decades ago, through a fundamentally technical justification, the LBB concept currently has been widely applied in nuclear installations projects in several countries. Based on the fracture mechanics, the LBB concept considers that a leakage from a crack can be detected before it reaches a critical size that implies the pipe failure, that is, the LBB analysis demonstrates through a technical justification that the probability of pipe rupture is extremely low. Among the aspects that involve the application of LBB, the main ones are: the definition of the material properties, which are obtained through tensile and fracture tests; the leakage analysis, which determines the rate of leakage due to the presence of a through-wall crack; and the analysis that verifies if the crack is stable considering the failure modes by ductile tear and plastic collapse. The materials SA-508 Cl. 3, SA-106 Gr. B and SA-376-TP304 were evaluated in relation to their performances for LBB. Data obtained from literature cases were used for the materials properties, and for the geometry and loadings of the pipe, all corresponding to the primary circuit of a PWR reactor. After application of the LBB, it was verified that all three materials met the limits established in the methodology. SA-508 Cl. 3 and SA-376-TP304 steels showed the best performance for ductile tear failure and plastic collapse failure, respectively, and SA-106 Gr. B steel had the lowest performance in both. All three materials presented plastic collapse as the most likely failure mode. In general, SA-376-TP304 steel presented the best performance for the LBB among the three materials evaluated in this work.
\end{abstract}

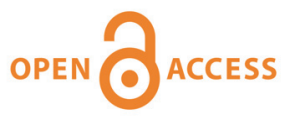

Citation: Silva, I. G. F, Andrade, A. H. P., Monteiro, W. A., Performance evaluation of different piping materials for application of Leak-Before-Break (LBB), Frattura ed Integrità Strutturale, 50 (2019) 46-53.

Received: 02.05.2019

Accepted: 09.07.2019

Published: 01.10.2019

Copyright: (C) 2019 This is an open access article under the terms of the CC-BY 4.0, which permits unrestricted use, distribution, and reproduction in any medium, provided the original author and source are credited. 
KEYWORDS. Leak-Before-Break; LBB; Piping material; Material performance; PWR reactor; Fracture mechanics.

\section{INTRODUCTION}

$\mathrm{N}$

uclear power plants use nuclear fission as a source of heat for energy production. Currently, 450 nuclear reactors are in operation in the world, producing about $400 \mathrm{GW}$ of electrical capacity; of these units in operation, 298 are PWR (Pressurized Water Reactor). In addition, 55 nuclear reactors are under construction, 45 of them being PWR [1].

The operating principle of a PWR nuclear plant is based on the removal of heat from the reactor core through a closed circuit of high pressure water, called the primary circuit. The water heated under high pressure in the primary circuit passes through a steam generator where it heats and turns into steam the water of the secondary circuit. This steam moves a turbine that drives an electric generator. The electricity generated reaches final consumers through distribution networks.

Pipes that are part of the PWR reactors are commonly manufactured from stainless steels or high toughness low alloy steels that are resistant to unstable defect growth. A crack in the piping should cause a leakage in a considerable amount, allowing its identification and quantification, before a growth can occur that would lead to a sudden rupture of the pipe. This is the essence of the Leak-Before-Break (LBB) concept. A fundamental step in the application of the LBB concept is the evaluation of the stability of postulated through-wall crack in a given pipe system. Because they are built using ductile materials, this evaluation is made through the concepts of Elastic-Plastic Fracture Mechanics (EPFM). Through a fundamentally technical justification, the LBB concept has been widely applied in nuclear installation projects in several countries $[2,3,4,5]$.

\section{LBB CONCEPT}

A ccording to the United States Atomic Energy Commission [6], the GDC (General Design Criterion) 4 requires that structures, systems, and components important for safety be designed to accommodate the environmental and dynamic effects associated with normal operation, and even with postulated accidents. It indicates that dynamic loading from the effects of these conditions, including missiles, pipe whipping, and discharging fluids must be verified in the designs.

In the case of primary circuit piping, the regulators of nuclear activity required, in the early 1970s, that nuclear plant designs take into account the hypothesis of a sudden rupture of the complete transversal section of a pipe (DEGB - Double-Ended Guillotine Break), causing a loss of coolant (LOCA-Loss-of-coolant Accident). This requirement, when applied to a high energy system, as the primary circuit of the reactor, demanded the consideration of two dynamic effects caused by sudden pipe rupture, whipping and jet effects. Thus, to protect the essential safety equipment of a nuclear plant, it was necessary the use of devices as pipe whip restraints and jet impingement shield.

For about a decade, the nuclear industry has sought solutions to disconsider the dynamic effects of a DEGB. So, the LBB methodology emerged as a technically justifiable approach to remove such analysis of the design bases of nuclear plants, leading to the realization of several studies between the 1970s and 1980s and acceptance by the regulators of nuclear activity [7].

The USNRC (United States Nuclear Regulatory Commission) established in the early 1980's the Pipe Break Task Group whose work culminated in the publication NUREG-1061 [8], which outlined the feasibility of applying the LBB concept. Based on this document, the document NUREG-0800-SRP 3.6.3 [9] was elaborated, where is characterized the deterministic evaluation procedure for application of the LBB concept proposed by the USNRC. These documents became a basic reference for the implementation of the criteria associated to the LBB concept in the American plants and, by extension, in other countries.

Since LBB is demonstrated, such ruptures can be excluded from the design bases, and the dynamic efforts resulting from LOCA are not considered in the structural analysis of the plant systems. As a result, it is no longer necessary to design components, equipment or piping supports of primary circuit to cope with such dynamic loads. Another advantage of the application of LBB is that pipe whip restraints and jet impingement shield, both required to protect important equipment 
from the dynamic effects of postulated rupture, can be removed. As the costs of these protection elements are high, and in some cases their existence makes it difficult or even impossible the in-service inspection of components, the withdrawal of the devices is desirable, not only for economic reasons, but also to reduce the dose of radiation received by maintenance staff [10].

Among the several points that involves the application of LBB, it is considered that its main aspects are the definition of the materials properties, leakage analysis, and stability analysis of the crack.

\section{MATERIALS AND METHODS}

\section{Evaluated materials}

mong the materials that have been used as base metal in primary circuits piping of PWR reactor SA-508 Cl. 3 (low alloy steel), SA-106 Gr. B (carbon steel) and SA-376-TP304 (stainless steel), were chosen to be evaluated due their different characteristics and chemical compositions according to the ASME [11].

\section{Applied methodology}

As established in NUREG-1061 [8] and NUREG-0800-SRP 3.6.3 [9], the methodology for applying LBB for each of the evaluated materials consisted basically of the following steps:

1) The tensile and fracture properties of the material were obtained from the stress versus strain curve and J-Integral versus crack extension curves (J-R curve), both according to the results of the literature cases that performed experiments with these materials.

2) The pipe loading considered was that in the section of the pipe where the combinations of stress and material properties are most unfavorable. This loading and piping geometry were extracted from the primary circuit of a PWR reactor described in a literature case.

3) A circumferential through-wall crack was postulated in this section.

4) The leakage detected by the plant monitoring system was multiplied by 10. In this work, it was considered that the plant has a leakage detection system of $1.0 \mathrm{gpm}$ (gallon per minute) where $1.0 \mathrm{gpm}=3.8$ liters $/$ minute.

5) The leakage analysis was performed for the cracks subjected to the normal operation loading to determine the crack size $\left(\mathrm{L}_{Q}\right)$ that causes the leakage of $10 \mathrm{gpm}$ (38 liters/minute). This analysis was done with the help of PICEP software [12].

6) Case 1: The elastic-plastic J-integral analysis was applied to verify the stability of 2 times the leakage crack size $\left(2 \mathrm{~L}_{\mathrm{Q}}\right)$ under normal operation loading plus SSE (Safe Shutdown Earthquake). Then it was possible to calculate its safety $\operatorname{margin}\left(\mathrm{M}_{1}=\mathrm{J}_{\mathrm{IC}} / \mathrm{J}_{1}\right)$, and $\mathrm{M}_{1} \geq 1.0$.

7) Case 2: The elastic-plastic J-integral analysis was applied to verify the stability of the leakage crack size $\left(\mathrm{L}_{Q}\right)$ under excessive loading, which is 1.414 times the normal operation loading plus SSE. Then it was possible to calculate its safety margin $\left(\mathrm{M}_{2}=\mathrm{J}_{\mathrm{IC}} / \mathrm{J}_{2}\right)$, and $\mathrm{M}_{2} \geq 1.0$.

8) Case 3: The limit load analysis was applied to obtain the critical crack size $\left(\mathrm{L}_{\mathrm{cr} 3}\right)$ under normal operation loading plus SSE. This was done with the help of PICEP software [12]. Then it was possible to calculate its safety margin $\left(\mathrm{M}_{3}=\mathrm{L}_{\mathrm{cr} 3} / \mathrm{L}_{\mathrm{Q}}\right)$, and $\mathrm{M}_{3} \geq 2.0$.

9) Case 4: The limit load analysis was applied to obtain the critical crack size $\left(\mathrm{L}_{\mathrm{cr} 4}\right)$ under excessive loading. This was done with the help of PICEP software [12]. Then it was possible to calculate its safety margin $\left(\mathrm{M}_{4}=\mathrm{L}_{\mathrm{cr} 4} / \mathrm{L}_{\mathrm{Q}}\right)$, and $\mathrm{M}_{4} \geq 1.0$.

After this application with each of the three materials, it was possible to evaluate their performances for LBB. This was done based on the lower safety margin (among the four calculated) presented by these materials, considering the ductile tear failure (elastic-plastic J-integral analysis) and the plastic collapse failure (limit load analysis). Thus, this margin corresponds to the most critical case, and to the most likely failure mode.

\section{Materials properties}

In this paper, the tensile and fracture properties of the evaluated materials are presented in Tab. 1, according to those referred cases. The same heat of material contemplates the tensile and fracture tests; the tests were performed at a temperature of $300^{\circ} \mathrm{C}\left( \pm 25^{\circ} \mathrm{C}\right)$; and the fracture test the pipe had a circumferential through-wall crack under bending moment loading. 
Applied loadings

The applied loadings used to apply the LBB in this paper correspond to the primary circuit of a PWR reactor. This information was obtained from Jong [13]. The reactor cooling system of this plant operates with internal pressure of 13 $\mathrm{MPa}$ and temperature of $300^{\circ} \mathrm{C}$, where the maximum stresses occurred in the pipe of NPS $10 \mathrm{SCH} 160 \mathrm{~S}$, being therefore, this piping geometry used in this work. Based on this case of the literature, the applied loadings which were considered for the application of LBB are presented in Tab. 2.

\begin{tabular}{ccccccccccc}
\hline Material & $\begin{array}{c}\text { Experiment } \\
\text { number }\end{array}$ & $\begin{array}{c}\mathrm{E} \\
{[\mathrm{GPa}]}\end{array}$ & $\begin{array}{c}\sigma_{0} \\
{[\mathrm{MPa}]}\end{array}$ & $\begin{array}{c}\sigma_{\mathrm{u}} \\
{[\mathrm{MPa}]}\end{array}$ & $\alpha$ & $\mathrm{n}$ & $\begin{array}{c}\mathrm{JIC} \\
{\left[\mathrm{kJ} / \mathrm{m}^{2}\right]}\end{array}$ & $\begin{array}{c}\mathrm{C} \\
{\left[\mathrm{kJ} / \mathrm{m}^{2}\right]}\end{array}$ & $\mathrm{m}$ & Ref. \\
SA-508 Cl. 3 & SFB2 & 188 & 410 & 579 & 1.26 & 8.98 & 652 & 724 & 0.51 & {$[14]$} \\
SA-106 Gr. B & IPIRG-2 1.8 & 193 & 216 & 506 & 1.38 & 5.05 & 305 & 88 & 1.00 & {$[15]$} \\
SA-376-TP304 & DP3-II 4131-1 & 183 & 131 & 459 & 9.58 & 3.21 & 745 & 255 & 0.86 & {$[15]$} \\
\hline
\end{tabular}

Table 1: Tensile and fracture properties.

\begin{tabular}{ccccc}
\hline Loading & $\begin{array}{c}\text { Axial force } \\
{[\mathrm{N}]}\end{array}$ & $\begin{array}{c}\text { Bending moment } \\
{[\mathrm{Nm}]}\end{array}$ & $\begin{array}{c}\text { Internal pressure } \\
{[\mathrm{MPa}]}\end{array}$ & $\begin{array}{c}\text { Total equivalent } \\
\text { moment }[\mathrm{Nm}]\end{array}$ \\
Normal operation & 15146 & 23769 & 13.0 & 51012 \\
Normal operation plus SSE & 22455 & 28293 & 13.0 & 55942 \\
Excessive & 31751 & 40006 & 18.4 & 79102 \\
\hline
\end{tabular}

Table 2: Applied loadings [13].

\section{Crack description}

The description of the postulated crack considered in this paper is presented in Tab. 3. This information was required for leakage analysis, which was done with the help of PICEP software [12].

\begin{tabular}{ccccc}
\hline $\begin{array}{c}\text { Orientation of } \\
\text { through-wall crack } \\
\text { Circumferential }\end{array}$ & $\begin{array}{c}\text { Crack cross- } \\
\text { sectional shape }\end{array}$ & $\begin{array}{c}\text { Ratio of the crack exit to } \\
\text { inlet areas }\end{array}$ & Entrance loss coefficient & $\begin{array}{c}\text { Surface } \\
\text { roughness [mm] }\end{array}$ \\
\hline
\end{tabular}

Table 3: Crack description.

\section{RESULTS}

\section{Leakage analysis}

7 he leakage analysis using PICEP software [12] determined the leakage rate curves versus crack size. According to the LBB methodology, the normal operating loading was considered in this step. The information of the materials properties and crack description were also used as input data for this software. The corresponding curve for each material is presented in Fig. 1.

This paper considered that the plant has a leakage detection system of $1.0 \mathrm{gpm}$. According to the LBB methodology, this leakage must be multiplied by 10 to determine the leakage crack size $\left(\mathrm{L}_{\mathrm{Q}}\right)$. The size and angle of the leakage crack to $10 \mathrm{gpm}$ for the evaluated materials are presented in Tab. 4.

\begin{tabular}{ccc}
\hline Material & Leakage crack size $-\mathrm{L}_{\mathrm{Q}}[\mathrm{mm}]$ & Leakage crack angle $\left[^{\circ}\right]$ \\
SA-508 Cl. 3 & 206.23 & 96.7 \\
SA-106 Gr. B & 207.17 & 97.1 \\
SA-376-TP304 & 149.82 & 70.2 \\
\hline
\end{tabular}

Table 4: Size and angle of the leakage crack to $10 \mathrm{gpm}$. 


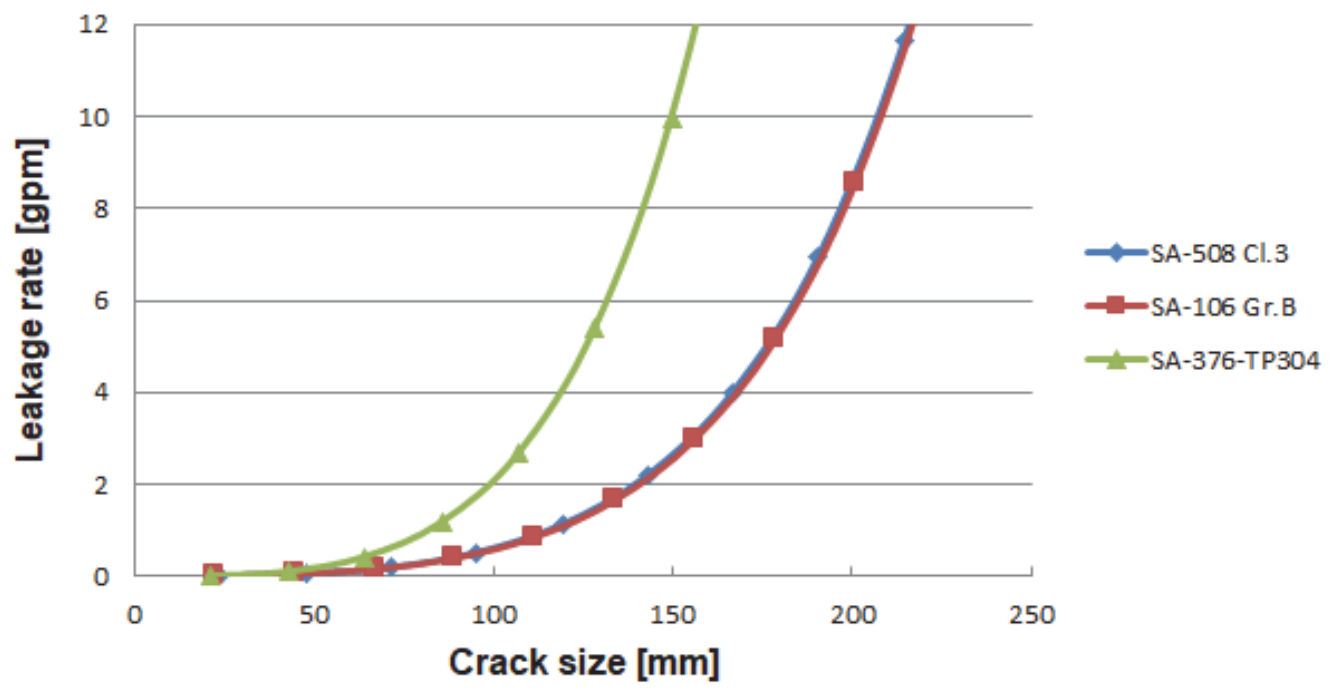

Figure 1: Leakage rate curves versus crack size.

\section{Elastic-plastic J-integral analysis}

After defining the leakage crack size $\left(\mathrm{L}_{\mathrm{Q}}\right)$, the elastic-plastic J-integral analysis was applied to verify the stability of the crack. Initially, this check consisted of the calculation of applied J-Integral according to Eq. 1 [16]. When it is smaller than JiC, the crack growth does not occur, but if it is equal to or greater than JIC, the tearing is initiated.

$$
J=\frac{f_{b} M^{2}}{R^{3} t^{2} E}+\alpha \sigma_{0} \varepsilon_{0} \pi R\left(1-\frac{\theta}{\pi}\right)^{2} H_{1}\left(\frac{M}{M_{0}}\right)^{n+1}
$$

Two applications of the elastic-plastic J-integral analysis were performed for each of the evaluated materials, called Case 1 and Case 2, defined according to the LBB application methodology. In Case 1, the verification considered the crack size of $2 \mathrm{~L}_{\mathrm{Q}}$ and normal operation loading plus SSE. In Case 2, the verification considered the crack size of $\mathrm{L}_{\mathrm{Q}}$ and excessive loading. Tabs. 5 and 6 present the details of the calculation for Case 1 and 2, respectively.

\begin{tabular}{ccccccccc}
\hline Material & $\theta[\mathrm{rad}]$ & $\mathrm{t}[\mathrm{m}]$ & $\mathrm{R}[\mathrm{m}]$ & $\mathrm{M}[\mathrm{Nm}]$ & $\mathrm{M}_{0}[\mathrm{Nm}]$ & $\mathrm{f}_{\mathrm{b}}$ & $\mathrm{H}_{1}$ & $\mathrm{~J} 1\left[\mathrm{~J} / \mathrm{m}^{2}\right]$ \\
SA-508 Cl. 3 & 1.6871 & 0.02857 & 0.12224 & 55942 & 117760 & 3.4603 & 0.6792 & 38672 \\
SA-106 Gr. B & 1.6948 & 0.02857 & 0.12224 & 55942 & 61148 & 3.7450 & 1.0480 & 57352 \\
SA-376-TP304 & 1.2256 & 0.02857 & 0.12224 & 55942 & 77742 & 1.5553 & 1.4880 & 65616 \\
\hline
\end{tabular}

Table 5: Details of the calculation of applied J-Integral for Case 1.

\begin{tabular}{ccccccccc}
\hline Material & $\theta[\mathrm{rad}]$ & $\mathrm{t}[\mathrm{m}]$ & $\mathrm{R}[\mathrm{m}]$ & $\mathrm{M}[\mathrm{Nm}]$ & $\mathrm{M}_{0}[\mathrm{Nm}]$ & $\mathrm{f}_{\mathrm{b}}$ & $\mathrm{H}_{1}$ & $\mathrm{~J}_{2}\left[\mathrm{~J} / \mathrm{m}^{2}\right]$ \\
SA-508 Cl. 3 & 0.8435 & 0.02857 & 0.12224 & 79102 & 377275 & 0.6041 & 0.6500 & 13486 \\
SA-106 Gr. B & 0.8474 & 0.02857 & 0.12224 & 79102 & 197998 & 0.6465 & 0.9410 & 14308 \\
SA-376-TP304 & 0.6128 & 0.02857 & 0.12224 & 79102 & 148949 & 0.3647 & 1.0560 & 24803 \\
\hline
\end{tabular}

Table 6: Details of the calculation of applied J-Integral for Case 2.

The safety margin was defined as the ratio between $\mathrm{JIC}_{\mathrm{IC}}$ and applied J-Integral, where $\mathrm{M}_{1}$ corresponds to the safety margin for Case 1, and $\mathrm{M}_{2}$ corresponds to the safety margin for Case 2. The performance evaluation of materials for elastic-plastic J-integral analysis was based on the values of these safety margins. Figs. 2 and 3 present the safety margin $\mathrm{M}_{1}$ and $\mathrm{M}_{2}$, respectively, for each of the evaluated materials. 


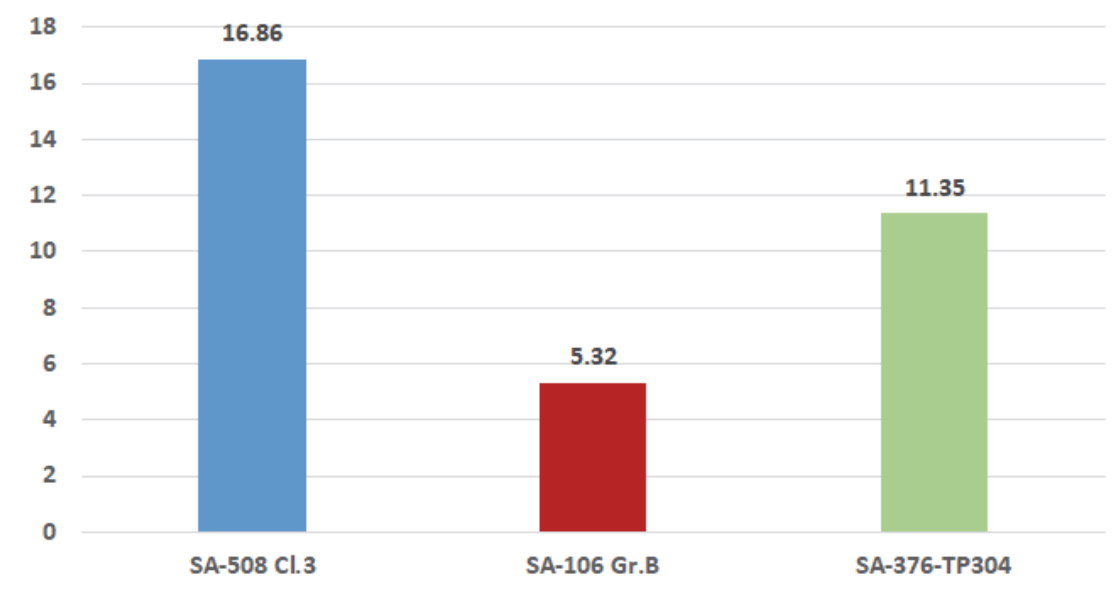

Figure 2: Safety margin $\mathrm{M}_{1}$.

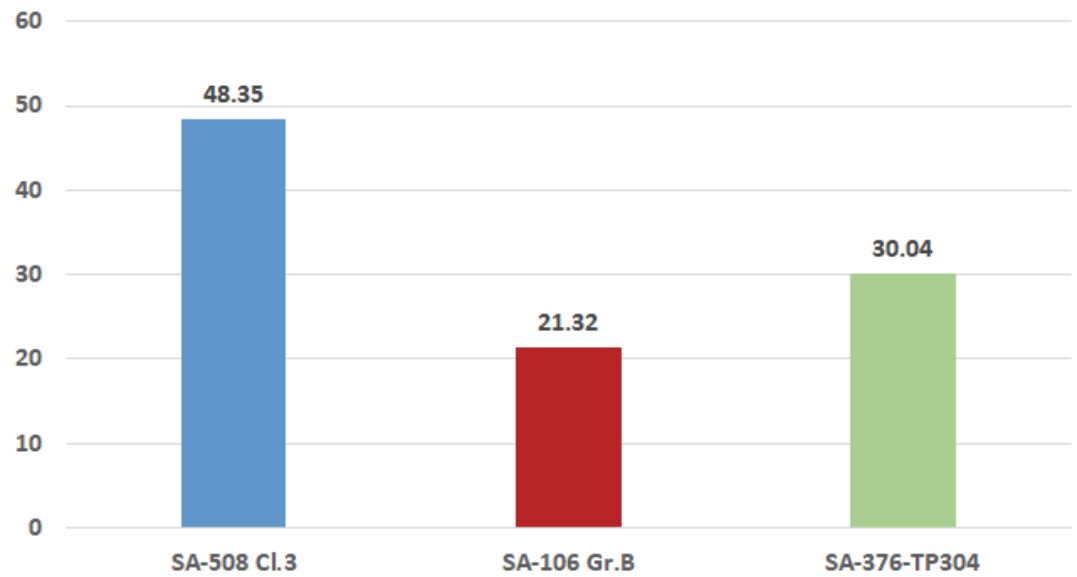

Figure 3: Safety margin $\mathrm{M}_{2}$.

\section{Limit load analysis}

The limit load analysis must also be applied to check for failure by plastic collapse. This application was performed with the help of PICEP software [12] to calculate the critical crack size $\left(\mathrm{L}_{\mathrm{cr}}\right)$.

Two applications of the limit load analysis were performed for each of the evaluated materials, called Case 3 and Case 4, defined according to the LBB methodology. In Case 3, the verification considered the normal operation loading plus SSE. In Case 4, the verification considered the excessive loading. Tab. 7 presents the calculated values for Case 3 and 4 , respectively.

\begin{tabular}{ccc}
\hline Material & $\begin{array}{c}\text { Critical crack size for Case 3 }-\mathrm{L}_{\mathrm{cr} 3} \\
{[\mathrm{~mm}]}\end{array}$ & $\begin{array}{c}\text { Critical crack size for Case } 4-\mathrm{L}_{\mathrm{cr} 4} \\
{[\mathrm{~mm}]}\end{array}$ \\
SA-508 Cl. 3 & 452.29 & 415.62 \\
SA-106 Gr. B & 421.73 & 378.94 \\
SA-376-TP304 & 415.62 & 378.94 \\
\hline
\end{tabular}

Table 7: Critical crack size for Cases 3 and 4.

The safety margin was defined as the ratio between $\mathrm{L}_{\mathrm{cr}}$ and $\mathrm{L}_{\mathrm{Q}}$, where $\mathrm{M}_{3}$ corresponds to the safety margin for Case 3 , and $\mathrm{M}_{4}$ corresponds to the safety margin for Case 4. The performance evaluation of materials for limit load analysis was based on the values of these safety margins. Figs. 4 and 5 present the safety margin $\mathrm{M}_{3}$ and $\mathrm{M}_{4}$, respectively, for each of the evaluated materials. 


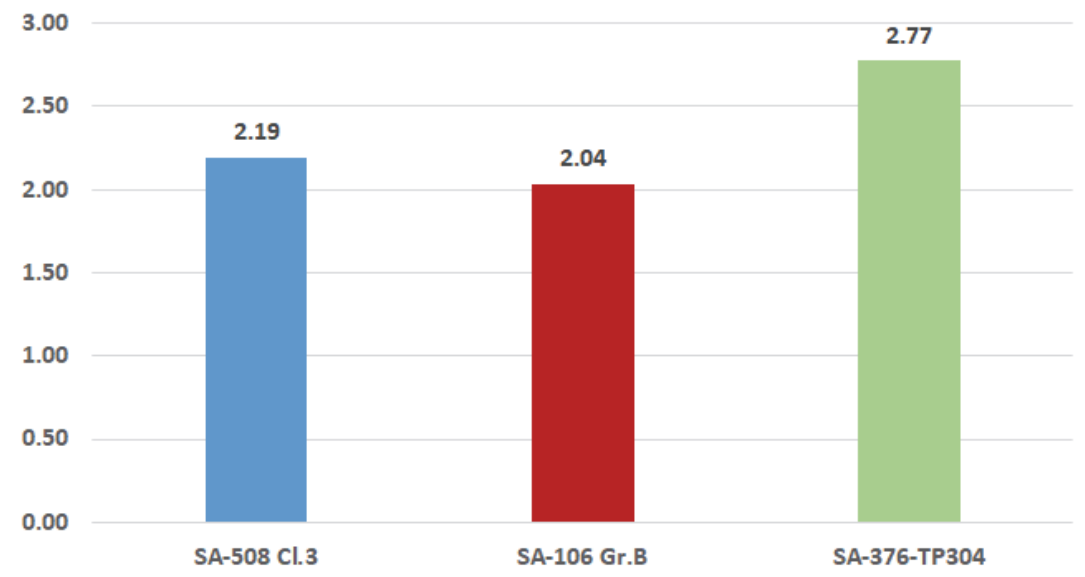

Figure 4: Safety margin $\mathrm{M}_{3}$.

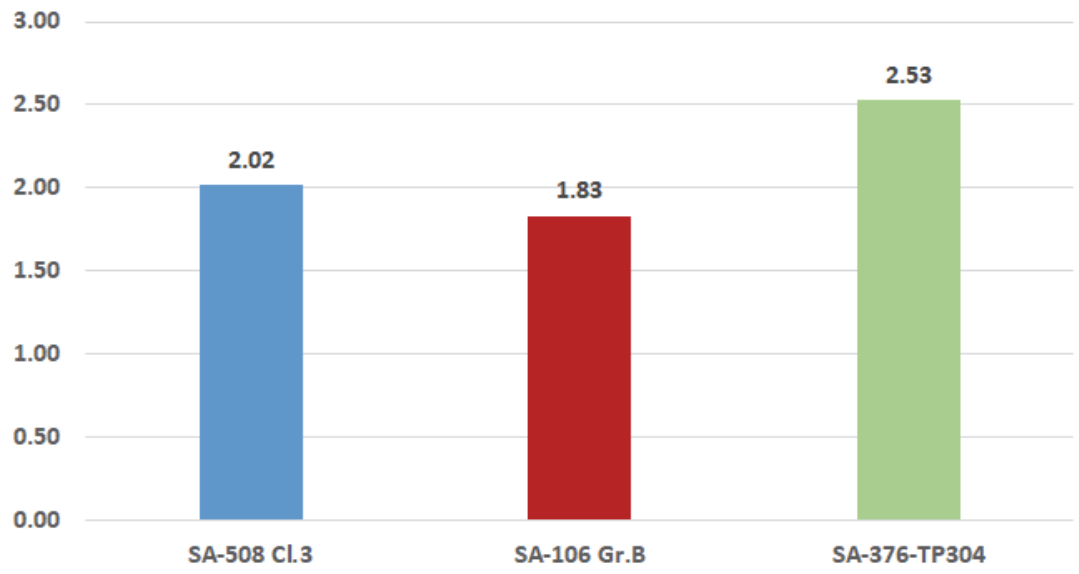

Figure 5: Safety margin $\mathrm{M}_{4}$.

\section{CONCLUSIONS}

$\mathrm{I}$

$\mathrm{n}$ the four cases, the safety margins of the evaluated materials have met the limits established in the methodology, that is, any of the three meets the minimum required and benefits from the advantages that the application of LBB can provide.

Among the materials evaluated and considering the two approached failure modes in the LBB methodology, SA-508 Cl. 3 and SA-376-TP304 steels showed the best performance for ductile tear failure and plastic collapse failure, respectively. In these two failure modes, SA-106 Gr. B steel showed the lowest performance of the three materials.

In all three materials, the most critical case and the most likely failure mode was Case 4 . This case considers excessive loading, and evaluates failure by plastic collapse. As SA-376-TP304 steel had the highest safety margin for this case, it was considered that this obtained the best performance for LBB among the three evaluated materials.

\section{REFERENCES}

[1] IAEA (2019). PRIS Database, Reactor Status Report. Available at: https://www.iaea.org/PRIS/WorldStatistics/OperationalReactorsByType.aspx

[2] Bourga, R., Moore, P., Janin, Y. J., Wang, B., Sharples, J. (2015). Leak-before-break: Global Perspectives and Procedures. International Journal of Pressure Vessels and Piping, 129-130, pp. 43-49. DOI: 10.1016/j.ijpvp.2015.02.004. 
[3] Heckmann, K., Sievers, J. (2018). Leak-before-break analyses of PWR and BWR piping concerning size effects. Nuclear Engineering and Design, 326, pp. 383-391. DOI: 10.1016/j.nucengdes.2017.11.027.

[4] Deschanels, H., Gilles, P., Kayser, Y., Pignol, M., Lacroix, R. (2017). Improvement of Leak-Before-Break Methodology for Sodium Fast Reactors. SMiRT 24, Busan, Korea.

[5] Liu, J., Wang, Y. (2017). Leak Before Break (LBB) Technology and Application in China Experimental Fast Reactor (CEFR). Mechanics and Materials Science, pp. 29-36. DOI: 10.1142/9789813228177_0004.

[6] United States Atomic Energy Commission (1971). 10 CFR Part 50 - Appendix A - General Design Criteria for Nuclear Power Plants.

[7] IAEA (1993). Applicability of the Leak Before Break Concept, IAEA, VIENNA, ISSN 1011-4289.

[8] NUREG-1061 (1984). Report of the U.S Nuclear Regulatory Commission Piping Review Committee, Evaluation of Potential for Pipe Breaks, Volume 3. USNRC.

[9] NUREG-0800-SRP 3.6.3 (1987). Leak-Before-Break Evaluation Procedures. USNRC.

[10] Maneschy, J. E., Miranda, C. A. J. (2014). Fracture Mechanics in Nuclear Industry. Lithos (in Portuguese).

[11] ASME (2013). ASME Boiler and Pressure Vessel Code, Section II, Part A, Ferrous Materials Specifications.

[12] Norris, D. M., Chexal, B. (1987). PICEP: Pipe Crack Evaluation Program. EPRI NP-3596-SR, Revision 1.

[13] Jong, R. P. (2004). Structural Integrity Assessment of Cracked PWR Piping Systems. M.Sc. Dissertation, Nuclear Technology Program, University of São Paulo (in Portuguese).

[14] Koyama, K.; Muroya, I.; Tanaka, T.; Nakamura, T. (1999). Low Alloy Steel Piping Test for Fracture Criteria of Leak Before Break. Nuclear Engineering and Design, 191, pp. 147-156.

[15] Miura, N. (1999). Approximate Evaluation Method for Ductile Fracture Analysis of a Circumferentially Through-WallCracked Pipe Subjected to Combined Bending and Tension. Nuclear Engineering and Design, 191, pp. $177-194$.

[16] Zahoor, A. (1989). Ductile Fracture Handbook. NP-6301-D Research Project, Electronic Power Research Institute.

\section{NOMENCLATURE}

E Young's modulus

$\sigma_{0} \quad$ Yield strength

$\sigma_{\mathrm{u}} \quad$ Tensile strength

$\varepsilon_{0} \quad$ Strain for $\sigma_{0}$

$\alpha \quad$ Strain hardening coefficient (parameter of Ramberg-Osgood's law)

n Strain hardening exponent (parameter of Ramberg-Osgood's law)

JIC J-Integral associated with the beginning of crack growth

C Constant of the J-R curve

$\mathrm{m} \quad$ Exponent of the J-R curve

$\mathrm{L}_{\mathrm{Q}} \quad$ Leakage crack size

$\mathrm{J}_{1} \quad$ Applied J-Integral for Case 1

$\mathrm{J}_{2} \quad$ Applied J-Integral for Case 2

$\mathrm{L}_{\mathrm{cr}} \quad$ Critical crack size (limit load analysis)

$\mathrm{L}_{\mathrm{cr} 3} \quad$ Critical crack size for Case 3

$\mathrm{L}_{\mathrm{cr} 4} \quad$ Critical crack size for Case 4

$\mathrm{M}_{1} \quad$ Safety margin for Case 1

$\mathrm{M}_{2} \quad$ Safety margin for Case 2

$\mathrm{M}_{3} \quad$ Safety margin for Case 3

$\mathrm{M}_{4} \quad$ Safety margin for Case 4

M Applied moment

$\mathrm{M}_{0} \quad$ Reference moment calculated according to ref. [16]

$\mathrm{Fb} \quad$ Correction factor calculated according to ref. [16]

$\mathrm{H}_{1} \quad$ Influence function calculated according to ref. [16]

$\mathrm{R} \quad$ Pipe mean radius

t Pipe wall thickness

$\theta \quad$ Crack half-angle 